Tropical Journal of Pharmaceutical Research October 2012; 11 (5): 713-719

(C) Pharmacotherapy Group Faculty of Pharmacy, University of Benin

Benin City, 300001 Nigeria.

All rights reserved.

Available online at http://www.tjpr.org

http://dx.doi.org/10.4314/tjpr.v11i5.3

Research Article

\title{
Development and Evaluation of Floating Microspheres of Curcumin
}

\author{
Kapil Kumar ${ }^{1^{*}}$ and AK Rai ${ }^{2}$ \\ ${ }^{1}$ Institute of Pharmacy NIMS University, Jaipur, 303121, Rajasthan, Global Institute of Pharmaceutical Education and \\ Research, Kashipur, U.K., ${ }^{2}$ Pranveer Singh Institute of Technology, Kanpur, U.P., India
}

\begin{abstract}
Purpose: To prepare and evaluate floating microspheres of curcumin for prolonged gastric residence time and increased drug bioavailability.

Methods: Floating microsphere were prepared by emulsion solvent diffusion method, using hydroxylpropyl methylcellulose (HPMC), ethyl cellulose (EC), Eudragit S 100 polymer in varying ratios. Ethanol/dichloromethane blend was used as solvent in a ratio of 1:1. The floating microspheres were evaluated for flow properties, particle size, incorporation efficiency, as well as in-vitro floatability and drug release. The shape and surface morphology of the microspheres were characterised by optical and scanning electron microscopy.

Result: The floating microspheres showed particle size, buoyancy, drug entrapment efficiency and yield in the ranges of $251-387 \mu \mathrm{m}, 74.6-90.6 \%$, and $72.6-83.5 \%$, and $45.5-82.0 \%$, respectively. Maximum drug release after $20 h$ was 47.1, 55.7, 69.4 and $81.3 \%$ for formulations F1, F2, F3 and F4, respectively. Scanning electron micrographs indicate pores both on the surface and interior of the microspheres.
\end{abstract}

Conclusion: The developed curcumin microsphere system is a promising floating drug delivery system for oral sustained administration of curcumin.

Keywords: Gastro-retentive, Sustained release, Curcumin, Floating microspheres; Ethyl cellulose, Hydroxylpropyl methylcellulose, Eudragit 


\section{INTRODUCTION}

In the past, herbal drugs did not attract researchers' interest for the development of novel drug delivery systems due to difficulties in processing (including standardization, extraction and identifycation). Recently however, with the advances in technology, new doors have been opened for the development of herbal drug delivery systems [1].

The floating microspheres beneficially alter the absorption of a drug, thus enhancing its bioavailability. They prolong dosing intervals which would allow development of once a day formulations and thereby increase patient compliance beyond the level of existing dosage forms by achieving control over gastric residence time [2-3]. Floating microspheres are gastroretentive drug delivery systems based on a non-effervescent approach. These microspheres are characteristically free-flowing powders having a size $<199 \mu \mathrm{m}$ and remain buoyant over gastric contents for a prolonged period. As the system floats over gastric contents, the drug is released slowly at the desired rate, resulting in increased gastric retention with reduced fluctuations in plasma drug concentration [4].

Studies have revealed that curcumin has broad range of therapeutic activities, including anti-inflammatory, antibacterial, antifungal, anticancer, antispasmodic and antioxidant [5]. Curcumin (isolated from Curcuma longa) is the active ingredient of the spice, turmeric, used in cooking in India and other regions of AsiaThe origin of the plant, Curcuma longa L. (which belongs to Zingiberaceae family) is India. Curcumin is a potent phytomolecule with a wide range of biological activities and shows low absorption [5]. It was selected for this study because it is poorly absorbed in the lower GIT and has a short elimination half-life of $0.39 \mathrm{~h}$. The poor bioavailability $(<1 \%)$ of the molecule owing to its insolubility at gastric $\mathrm{pH}$ and degradation at alkaline $\mathrm{pH}$ of intestine in the humans, has severely limited its clinical application. High oral doses (8 g/day) in humans result in $\mathrm{C}_{\max }$ of $<2 \mu \mathrm{M}$, and short half life $(28 \mathrm{~min})$ limit its use via the oral route [6].

\section{EXPERIMENTAL}

Curcumin was a gift sample from Krish Enteprizes, Mumbai, India. HPMC and Eudragit S 100 were received as a gift samples from Glukem Pharmaceuticals $(P)$ Ltd, India. All other chemicals used were of analytical grade.

\section{Preparation of floating microspheres}

Floating microspheres were prepared by emulsion solvent diffusion method [7]. Briefly, the drug and polymer blends were mixed in the solvent (ethanol/dichloromethane, 1:1) as per the composition in Table 1 . The resulting slurry was introduced into a $250 \mathrm{ml}$ beaker containing $200 \mathrm{ml} 0.2$ $\%$ sodium lauryl sulfate SLS and stirred at $750 \mathrm{rpm}$ with a mechanical stirrer for $1 \mathrm{~h}$ at room temperature. The floating microspheres were collected by decantation, washed thrice with n-hexane, dried overnight in an oven at $40 \pm 2{ }^{\circ} \mathrm{C}$, and stored in a desiccator containing calcium chloride as desiccant.

Table 1: Composition of the formulations

\begin{tabular}{lcccc}
\hline Material (mg) & F1 & F2 & F3 & F4 \\
\hline Eudragit S100 & 250 & 500 & 750 & - \\
Ethyl cellulose & - & - & 250 & 500 \\
HPMC & - & - & 250 & 250 \\
\hline
\end{tabular}

Note: Each formulation contained $250 \mathrm{mg}$ of curcumin; The ingredients were dissolved in $10 \mathrm{ml}$ of a solvent system, dichloromethane:ethanol (1:1)

\section{Measurement of particle size}

Particle size was measured by microscopic technique. In this method, a suspension of floating microspheres was prepared using castor oil. A drop of the suspension was mounted on a slide and observed under 
optical microscope; about 600 particles were measured with the aid of an eye-piece micrometer. All the microspheres in a field were counted [8].

\section{Measurement of bulk density}

Bulk density is determined by pouring presieved microspheres into a graduated cylinder via a large funnel and measure the volume and weight.

\section{Measurement of tapped density}

A known weight of the microspheres was transferred to a measuring cylinder, tapped manually 100 times, and the the ratio of weight to volume of the microspheres gives the tapped density [9].

\section{Determination of Carr's index (Compre- ssibility)}

This parameter was computed from tapped (DT) and bulk density (DB) data of the microspheres as in Eq 1 [10]

Carr's index $=\{(\mathrm{DT}-\mathrm{DB}) / \mathrm{DT}\} 100$

\section{Determination of Hausner ratio}

The Hausner ratio of the microspheres was determined from the ration of tapped density to bulk density.

\section{Evaluation of angle of repose}

The angle of repose of the microspheres, which measures the resistance to particle flow, was determined by the fixed funnel method. The height of the funnel was adjusted in such a way that the tip of the funnel just touches the heap of the blends. An accurately weighed sample of the microspheres was allowed to pass through the funnel freely on to a flat surface. The height $(h)$ and radius $(r)$ of the powder cone were measured and the angle of repose $(\theta)$ calculated using Eq 2 [11]. $\theta=\tan ^{-1} \frac{h}{r}$

\section{Scanning electron microscopy}

Scanning electron microscopy was carried out on formulations F5. The dry microspheres were placed on a brass stub coated with gold in an ion sputter and scanned using JEOL - 6360A scanning electron microscope at an accelerating voltage of $20 \mathrm{KV}$ [12]

\section{Drug entrapment efficiency (DEE)}

The amount of drug entrapped in $50 \mathrm{mg}$ of microspheres was evaluated by crushing the microspheres and extracting with aliquots of $0.1 \mathrm{~N} \mathrm{HCl}$ and $0.2 \%$ sodium lauryl sulfate (SLS) repeatedly as curcumin is soluble in SLS. The extract was transferred to a 100 $\mathrm{ml}$ volumetric flask and the volume was made up using $0.1 \mathrm{~N} \mathrm{HCl}$. The solution was filtered by Whatman filter paper of pore size $0.02 \mu \mathrm{m}$ and the absorbance measured spectrophotometrically (Shimadzu 1700) at $254 \mathrm{~nm}$. The drug entrapped (DEE, \%) in the microspheres was calculated using Eq 3.

$\mathrm{DEE}=(\mathrm{AA} / \mathrm{TA}) 100$

where $A A$ is the actual amount present in the microspheres and TA is the theoretical amount.

\section{Determination of microsphere yield}

Microspheres with a size range of 251-388 $\mu \mathrm{m}$ were prepared and weighed. The ratio of the weight to the total weight of all the nonvolatile ingredients used for the preparation of the microspheres, expressed as a percentage, was taken as the yield.

\section{Assessment of in-vitro buoyancy}

Microspheres (300 mg) were spread over the surface of a USP XXIV dissolution apparatus type II filled with $900 \mathrm{ml}$ of $0.1 \mathrm{~N}$ 
hydrochloric acid containing $0.02 \%$ Tween 80 . The medium was agitated with a paddle rotating at $100 \mathrm{rpm}$ for $12 \mathrm{~h}$. The floating and the settled fractions of microspheres were recovered separately, dried and weighed. Buoyancy (\%) was calculated as the ratio of the mass of the microspheres that remained floating to the total mass of the microspheres, expressed as a percentage [13].

\section{In-vitro drug release studies}

A modified USP XXIV dissolution apparatus type I (basket) was used to study in vitro drug release from the microspheres. The test was carried out separately at $100 \mathrm{rpm}$ in distilled water and $1 \mathrm{M} \mathrm{HCl}(\mathrm{pH} 1.2)$ as dissolution media $(900 \mathrm{ml})$ maintained at 37 $\pm 1{ }^{\circ} \mathrm{C}$. Samples ( $2 \mathrm{ml}$ each) were withdrawn at intervals and analyzed spectrophotometrically at $254 \mathrm{~nm}$. The release medium was replenished with the same amount of fresh medium to maintain sink conditions. All experiments were performed in triplicate. Cumulative drug release (\%) was calculated from a standard curve [14].

\section{Statistical analysis}

To ascertain drug release mechanism and release rate, the data were model fitted to various release models - zero order (Eq 4), first order (Eq 5), Higuchi (Eq 6) and Korsmeyer-Peppas (Eq 7) using PCP Disso V3.0 dissolution software [15].

Release rate $=\mathrm{k}$

Release rate $=k[\mathrm{~A}]$

Release rate $=\mathrm{kt}^{0.5}$

Release $=\mathrm{kt}^{\mathrm{n}}$

where $\mathrm{k}$ is a constant, $\mathrm{A}$ is concentration of reactant, $\mathrm{n}$ is the release exponent, $\mathrm{t}$ is time.

\section{RESULTS}

\section{Physicochemical characteristics of microspheres}

The physicochemical characterizatics of the floating microdpheres are shown in Tables 2 and 3 as well as Fig 1 . The microspheres were discrete and free flowing. The mean arithmetic diameter varied between 251 and $388 \mu \mathrm{m}$.

The yield of floating microspheres was in the range of 45.5 - 82.0 which indicates the percentage yield increased with increasing the polymer concentration while drug entrapment efficiency ranged from 72.6 to $83.5 \%$. It was found that the entrapment efficiency increased with increasing amount of polymers in the hollow microspheres i.e. batch F3 and F4.

Table 2: Characteristics of floating curcumin microspheres

\begin{tabular}{lllll}
\hline Formulation & Yield (\%) & $\begin{array}{l}\text { Entrapment } \\
\text { efficiency (\%) }\end{array}$ & Angle of repose $\left(^{\circ}\right.$ ) & Buoyancy (\%) \\
\hline F1 & $45.46 \pm 0.158$ & $72.6 \pm 0.1$ & $18.5 \pm 0.0$ & $74.6 \pm 0.2$ \\
F2 & $62.12 \pm 0.147$ & $78.3 \pm 0.1$ & $19.5 \pm 0.0$ & $80.3 \pm 0.3$ \\
F3 & $75.56 \pm 0.085$ & $80.2 \pm 0.1$ & $21.9 \pm 0.1$ & $83.6 \pm 0.3$ \\
F4 & $82.02 \pm 0.079$ & $83.5 \pm 0.1$ & $23.0 \pm 0.7$ & $90.6 \pm 0.2$ \\
\hline
\end{tabular}

Table 3: Micromeritic properties of curcumin floating microspheres

\begin{tabular}{|c|c|c|c|c|c|}
\hline $\begin{array}{l}\text { Formulati } \\
\text { on }\end{array}$ & $\begin{array}{l}\text { Particle } \\
\text { size }(\mu \mathrm{m})\end{array}$ & $\begin{array}{l}\text { Bulk density } \\
\left(\mathrm{g} / \mathrm{cm}^{3}\right)\end{array}$ & $\begin{array}{l}\text { Tapped density } \\
\left(\mathrm{g} / \mathrm{cm}^{3}\right)\end{array}$ & $\begin{array}{l}\text { Hausner } \\
\text { ratio }\end{array}$ & Carr's index \\
\hline $\begin{array}{l}\text { F1 } \\
\text { F2 } \\
\text { F3 } \\
\text { F4 }\end{array}$ & $\begin{array}{l}251 \pm 2 \\
266 \pm 4 \\
325 \pm 6 \\
388 \pm 8\end{array}$ & $\begin{array}{l}0.150 \pm 0.040 \\
0.168 \pm 0.004 \\
0.166 \pm 0.005 \\
0.176 \pm 0.009\end{array}$ & $\begin{array}{l}0.166 \pm 0.253 \\
0.216 \pm 0.030 \\
0.214 \pm 0.016 \\
0.200 \pm 0.536\end{array}$ & $\begin{array}{l}1.11 \pm 0.03 \\
1.29 \pm 0.01 \\
1.29 \pm 0.01 \\
1.14 \pm 0.14\end{array}$ & $\begin{array}{l}9.64 \pm 0.04 \\
22.58 \pm 0.53 \\
22.43 \pm 0.00 \\
12.0 \pm 0.01\end{array}$ \\
\hline
\end{tabular}


SEM indicates that the microspheres were spherical with a smooth surface; distinct pores were evident on the surface of microspheres, which will be responsible for the release. The photomicrographs also showed the presence of loose crystals of drug on the surface of a few microspheres

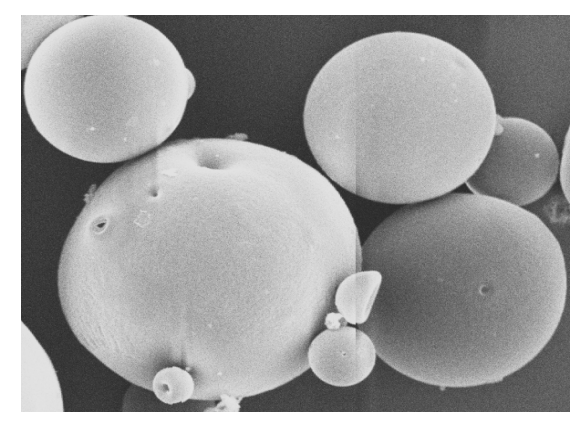

Figure 1: SEM of prepared floating microsphere formulation F4

\section{Drug release}

Cumulative drug release after $20 \mathrm{~h}$ for formulation F4, F1, F2 and F3 was 81.3, $47.1,55.7$ and $69.4 \%$, respectively. Eudragit S100 (an anionic copolymer of methacrylic acid and methyl methacrylate containing free carboxylic and ester groups [16]) is insoluble in acidic medium and also exhibits low permeability.

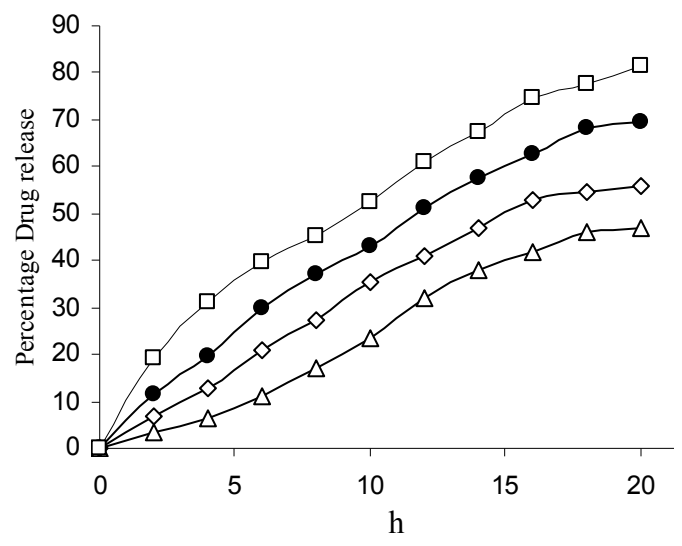

Figure 2: Drug release profiles of curcumin from floating microspheres (Note: F1 $=\Delta$, F2 $=\diamond$, F3 $=\bullet, F 4=\square)$

In all the cases, the best-fit model was found to be Korsmeyer-Peppas with ' $n$ ' value between 0.65 to 0.73 (Table 4) suggesting a non-Fickian (anomalous) release mechanism $(0.5<\mathrm{n}<1)$ for the drug, i.e., erosion followed by diffusion controlled release.

Table 4: In-vitro drug release kinetics of the formulations

\begin{tabular}{lccccccccc}
\hline $\begin{array}{l}\text { Batch } \\
\text { code }\end{array}$ & \multicolumn{2}{c}{$\begin{array}{c}\text { Zero order } \\
\text { model }\end{array}$} & \multicolumn{2}{c}{$\begin{array}{c}\text { First order } \\
\text { model }\end{array}$} & \multicolumn{2}{c}{ Higuchi model } & \multicolumn{2}{c}{$\begin{array}{c}\text { Korsmeyer-Peppas } \\
\text { model }\end{array}$} \\
& $\mathrm{R}$ & $\mathrm{K}$ & $\mathrm{R}$ & $\mathrm{K}$ & $\mathrm{R}$ & $\mathrm{K}$ & Slope $(\mathrm{n})$ & $\mathrm{R}$ & $\mathrm{K}$ \\
\hline $\mathrm{F} 1$ & 0.8361 & 1.13 & 0.9850 & -0.07 & 0.9623 & 10.03 & 0.6761 & 0.9651 & 5.01 \\
F2 & 0.8024 & 1.16 & 0.9821 & -0.03 & 0.9553 & 8.72 & 0.6855 & 0.9688 & 5.09 \\
F3 & 0.9152 & 1.25 & 0.9823 & -0.02 & 0.9838 & 10.06 & 0.6671 & 0.9752 & 4.08 \\
F4 & 0.9021 & 1.38 & 0.9862 & -0.01 & 0.9827 & 10.00 & 0.6746 & 0.9651 & 6.15
\end{tabular}

\section{DISCUSSION}

In the present study four different batches of floating microspheres of curcumin were formulated using different polymer i.e. eudragit S 100, ethyl cellulose and HPMC by emulsion solvent diffusion method. The physical characterization, floating behavior and in vitro release studies were studied.
Angle of repose, Hausner ratio, and Carr's index can be used to predict flowability. The higher the Hausner ratio the greater the cohesion between particles while the higher the Carr's index of the greater the tendency to form bridges between particles. 
Floating microspheres of batch $\mathrm{F} 4$ were spherical in shape. The porous nature of the floating microspheres and the spherical shape of the microspheres are evident from their SEM photomicrographs (Figure 1).

Buoyancy for all the formulations was $\geq 74 \%$ after $12 \mathrm{~h}$. The nature of the polymer influenced the floating behavior of the microspheres. Microspheres of batch F1 containing eudragit RS 100 were least buoyant. In general with increase in the amount of polymers there is an increase in the buoyancy percentage. The increase in the buoyancy percentage may be attributed to air which caused swelling because of increased amount of the polymers present. The good buoyancy behavior of the microspheres may be attributed to the hollow nature of the microspheres.

Formulations containing larger amount of polymer i.e. batch F3 and F4 shows more entrapment efficiency. Due their floating nature, the microspheres were forcibly immersed into the dissolution medium to avoid adherence to the surface of the jar, thus leading to nonparticipation in the dissolution process. The drug release was extended to $20 \mathrm{~h}$. Microspheres prepared with ethyl cellulose and HPMC, (F3 and F4) showed more release in comparison to those prepared with eudragit S 100 this may be attributed to poor water solubility of eudragit S 100.

The data obtained for in vitro release were fitted into equations for the zero-order, first order, Korsmeyer Peppas and Higuchi release models. The interpretation of data was based on the value of the resulting regression coefficients. The in vitro drug release showed the highest regression coefficient values for Korsmeyer Peppas model. It indicates that non-fickcian diffusion is the mechanism of drug release.

In a previous study Rahman et al developed a floating microspheres of curcumin using HPMC K100 and poloxamer 188 using emulsion/solvent evaporation method [17]. Studies conclude that curcumin loaded floating microspheres can be used as a drug delivery system to improve the absorption kinetics of curcumin.

\section{CONCLUSION}

Curcumin floating microspheres were successfully developed using emulsion solvent diffusion method. The microspheres had good yield and showed high, drug entrapment efficiency. The flow properties of microspheres were within the acceptable range and therefore would be easily filled into capsules. Release properties were satisfactory and the formulations hold promise for further development into drug delivery systems for oral administration of curcumin.

\section{ACKNOWLEDGEMENT}

The authors are thankful to Dr AK Saxena, Chief Scientist, CDRI, Lucknow, India for his technical advice and motivation during the work, and Mr. Arpit Sharma GIPER, Kashipur, India for secretarial support.

\section{REFERENCES}

1. Norman GB. Herbal drugs and phytopharmaceuticals. A Handbook for Practice on a Scientific Basis. New York: Medpharm Scientific Publishers, Stuttgart and CRC Press, 2001; 2: 230-48.

2. Chien YW. Novel drug delivery system, Marcel Dekker Inc Publications: New York, 1992; 2(50): 16172.

3. Khar RK, Vyas SP. Targeted and controlled drug delivery novel carrier system, CBS Publishers and Distributors: New Delhi, 2002; 1: 417-54.

4. Arora S, Ali J, Ahuja A, Khar RK, Baboota S. Floatng drug delivery systems: A review, AAPS Pharm Sci Tech 2005; 6(3): 372-390.

5. Wahlstrom B, Blennow G. A study on the fate of curcumin in the rat, Acta Pharmacol Toxicol, 1978; 43: 86-92.

6. Anand $P$, Kunnumakkara $A B$, Newman RA. Bioavailability of Curcumin: Problems and Promises, Mol Pharmaceutics, 2007; 4 (6): 807-818.

7. Kawashima $Y$, Niwa $T$, Takeuchi $H$, Hino $T$, Itoh $Y$. Hollow microspheres for use as a floating 
controlled drug delivery system in the stomach, Pharm Sci, 1992; 81: 135-140.

8. Parasuram RR, Moidutty L, Chetan H. Preparation and evaluation of delayed release aceclofenac microspheres, Asian J Pharm, 2008; 2(4): 52-54.

9. Aulton ME, Pharmaceutics: The Science of Dosage Form Design, Churchill Livingstone ,Elsevier Science Ltd, 2002; 2:315-2320.

10. Trivedi $P$, Verma ML, Garud N. Preparation and characterization of aceclofenac microspheres, Asian J Pharm, 2008; 2: 110-115

11. Patel AR, Mahajan AN, Shah DA. Preparation and in vitro characterization of porous carrierbased floating microspheres of model drug for gastric delivery, Der Pharmacia Lettre, 2011; 3(3):432-42.

12. Pusp RN, Myung K C, Hoo K C. Preparation of floating microspheres for fish farming, Int $J$ Pharm, 2007; 341: 85-90.
13. Srivastava A, Floating microspheres of cimetidine: formulation, characterization and in vitro evaluation, Acta Pharm, 2005; 55: 277-285.

14. Maheswari U, Jain S, Bhadra D, Jain NK. Floating microspheres bearing acetohydroxamic acid for the treatment of $H$. pylori, J Pharm Pharmacol, 2003; 55: 1607-1613.

15. Higuchi WI. Analysis of data on the medicament release from ointments, J Pharm Sci, 1962; 51:802-804

16. Korsmeyer RW, Gurny R, Doelker EM, Buri $P$, Peppas NA. Mechanism of solute release from porous hydrophilic polymers. Int $J$ Pharm, 1983; 15: 25-35.

17. Rahman MH, Telny $T$, Kumaraswamy $K$. Comparative evaluation of HPMC K100 and poloxamer 188 - influence on release kinetics of Curcumin in floating microspheres, $R \mathrm{~J}$ Pharm Chem Biol Sci, 2010;1(2): 28-34. 